\title{
Differential Regulation of Adipose Tissue Glucose Transporters in Genetic Obesity (Fatty Rat)

\author{
Selective Increase in the Adipose Cell/Muscle Glucose Transporter (GLUT 4) Expression
}

I. Hainault, M. Guerre-Millo, C. Guichard, and M. Lavau

INSERM U 177, Institut Biomédical des Cordeliers, 75006 Paris, France

\begin{abstract}
Adipocytes from young obese Zucker rats exhibit a hyperresponsive insulin-mediated glucose transport, together with a marked increase in cytochalasin B binding as compared with lean rat adipocytes. Here, we examined in these cells the expression of two isoforms of glucose transporter, the erythroid (GLUT 1) and the adipose cell/muscle (GLUT 4) types, in rats aged 16 or $30 \mathrm{~d}$, i.e., before and after the emergence of hyperinsulinemia. GLUT 1 protein and mRNA levels were identical in the two genotypes at both ages. In contrast, the levels of GLUT 4 protein in obese rat adipocytes were 2.4 - and 4.5 -fold those of lean littermates at 16 and $30 \mathrm{~d}$ of age, respectively, in perfect agreement with the genotype effect on insulin-stimulated glucose transport activity. The levels of GLUT 4 mRNA per fat pad were increased 2.3- and 6.2-fold in obese vs. lean rats 16and 30-d-old, indicating a pretranslational level of regulation. The obese phenotype was not associated with overexpression of GLUT 4 mRNA in gastrocnemius muscle. This work indicates that the fa gene exerts a differential control on the expression of GLUT 1 and GLUT 4 in adipose tissue and provides evidence that independent of hyperinsulinemia, genotype is a major regulatory factor of GLUT 4 expression in this tissue. ( $J$. Clin. Invest. 1991. 87:1127-1131.) Key words: glucose transport • erythroid glucose transporter (GLUT 1) • hyperinsulinemia • muscle GLUT 4 • suckling Zucker rat
\end{abstract}

\section{Introduction}

Adipocytes from young genetically obese Zucker rats (fatty rats) exhibit, under physiological concentrations of insulin, a severalfold increase in glucose transport activity both in vitro and in vivo, as compared to fat cells from their lean littermates $(1,2)$. This alteration could be responsible for the compelling

This work was presented in part at the 1990 Annual Meeting of the European Association for the Study of Diabetes in Copenhagen, Denmark, 10-13 September 1990 and published in abstract form (1990. Diabetologia. 33 Suppl.: A32).

Address correspondence to Dr. M. Lavau, INSERM U 177, Institut Biomédical des Cordeliers, 15 rue de l'Ecole de Médecine, 75006 Paris, France.

Received for publication 30 July 1990 and in revised form 18 October 1990 .

J. Clin. Invest.

(c) The American Society for Clinical Investigation, Inc. $0021-9738 / 91 / 03 / 1127 / 05 \$ 2.00$

Volume 87, March 1991, 1127-1131 shunting of glucose into adipose tissue triglycerides that characterizes the obese phenotype in the Zucker rat. Therefore, the elucidation of the underlying mechanism of enhanced glucose transport activity in fatty rat adipocytes is of critical importance in the understanding of the biochemical lesion of this genetic disorder.

Measurements of glucose transporters by the cytochalasin B binding method, have shown that the intracellular pool of glucose transporters was dramatically enlarged in those adipocytes, allowing enhanced translocation in response to insulin (1). Recent evidences indicate that at least two glucose transporter species are present in adipocytes: the erythroid type (GLUT 1), ${ }^{1}$ an ubiquitous protein which is predominantly expressed in erythrocytes and brain (3-5), and the adipose cell/ muscle type (GLUT 4), which is expressed exclusively in tissues that exhibit insulin-dependent glucose transport: fat and muscles (6-10). Differential regulation of these two glucose transporters in vivo has been documented recently in adipocytes; changes in insulinemia levels, by streptozotocin and insulin treatment, induced parallel changes in GLUT 4 protein and mRNA, whereas GLUT 1 expression was relatively unaffected (11-14). Likewise fasting and refeeding was shown to specifically modulate the expression of the GLUT 4 gene $(12,13)$.

We have addressed here the question of genotype as a regulatory factor in the expression of GLUT 1 and GLUT 4 at protein and mRNA levels, in adipose tissue of Zucker rats. To assess the effect of the fatty genotype independently of the hyperinsulinemia that characterizes postweaning obese Zucker rats, we have compared the expression of these genes in 16-dold rats and 30-d-old rats, i.e., before and after the emergence of hyperinsulinemia (15). Our data indicate that the fatty genotype increases glucose transport through a selective pretranslational effect on GLUT 4 gene independent of hyperinsulinemia.

\section{Methods}

Animals. Obese (fa/fa) Zucker rats and their lean ( $\mathrm{Fa} / \mathrm{fa})$ littermates were obtained by breeding heterozygous females and obese males. The initial breeding pairs were obtained from Harriet G. Bird Memorial Hospital, Stow, MA. Pups had access to the dam's diet (normal rat chow, UAR, Epinay/Orge, France) and were separated from their mother at $28 \mathrm{~d}$ of age. For each experiment, two to six litters were

1. Abbreviations used in this paper: $\mathrm{FA} / \mathrm{fa}$, lean Zucker; $\mathrm{rat}, \mathrm{fa} / \mathrm{fa}$, obese Zucker rat; GLUT 1, erythroid-type glucose transporter; GLUT 4, adipose cell/muscle-type glucose transporter. 
selected, with 10 pups of both sexes in each. Male and female pups were used undistinguished. The genotypes were diagnosed by plotting adipose tissue weight against body weight in 16-d-old pups (16), and on the basis of fat pad weight in 30-d-old rats. Rats were killed between 09:00 and $11: 00 \mathrm{~h}$, by decapitation.

Glucose transport in isolated adipocytes. For each experiment, subcutaneous inguinal adipose tissues, the only fat depots to be developed in young rats, were removed from several animals and pooled according to the rat genotype. Adipose cells were isolated by the collagenase method of Rodbell (17) and glucose transport was measured by using 6 ${ }^{14} \mathrm{C}$ glucose $(50 \mu \mathrm{M})$, as previously described (18). Adipose cell size was determined by a microphotographic method (19).

Preparation of membranes and Western blot analysis. Plasma and low-density microsomal membranes were prepared from isolated adipocyte homogenates, as previously described (1), except that protease inhibitors $(0.1 \mathrm{mM}$ PMSF and $25 \mu \mathrm{g} / \mathrm{ml}$ pepstatin) were added to homogeneization medium. Total membranes were prepared by centrifugation of isolated adipocyte homogenates at $200,000 \mathrm{~g}$ for $60 \mathrm{~min}$. The proteins were assayed by the Bio-Rad Laboratories (Richmond, CA) protein determination method. Membrane proteins were subjected to SDS-PAGE using a $12 \%$ polyacrylamide resolving gel and transferred onto Immobilon filters (Millipore Corp., Bedford, MA). The blots were immunoblotted, using either an antibody against the $\mathrm{COOH}$-terminal peptide of GLUT 1 obtained from Dr. S. W. Cushman (20), or a monoclonal antibody (1F8) against GLUT 4 obtained from Dr. P. F. Pilch (6). Immunolabeled bands were visualized and counted as previously described (21).

RNA isolation and Northern blot analysis. Total RNA was extracted by the guanidinium isothiocyanate $/ \mathrm{LiCl}$ method of Cathala et al. (22), either from total inguinal adipose tissue or from the two cellular fractions of this tissue, the collagenase-isolated adipocytes and the stroma-vascular cells which were recovered by centrifugation of adipocyte infranatants $\left(1,000 g_{\max }\right.$ for $\left.5 \mathrm{~min}\right)$. In some rats, the skeletal muscle gastrocnemius was also dissected out for RNA preparation. RNA was electrophoresed on $1.2 \%$ formaldehyde agarose gels, blotted, and fixed onto nylon filters (Hybond N+, Amersham, Les Ullis, France). Hybridizations were performed either with a rat brain glucose transporter cDNA obtained from Dr. M. J. Birnbaum (4) or with a rat muscle glucose transporter cRNA probe obtained from Dr. M. J. Charron (8), under stringent conditions. Blots were also hybridized with $\beta$-actin cDNA. The relative amount of each mRNA was quantified by scanning densitometry (Cliniscan).

\section{Results}

Body weight was only slightly increased in 16-d-old obese Zucker rats as compared to lean littermates $(22.4 \pm 0.27$ vs. $20.4 \pm 0.30 \mathrm{~g} ; P<0.01$ ) but the weight of the inguinal adipose tissue (two pads) was already markedly higher than in lean pups $(0.31 \pm 0.02$ vs. $0.13 \pm 0.01 \mathrm{~g} ; P<0.01)$. At $30 \mathrm{~d}$ of age, body weights were higher in $\mathrm{fa} / \mathrm{fa}$ rats than in lean littermates $(68.5 \pm 2.1$ vs. $56.4 \pm 5.2 \mathrm{~g} ; P<0.01)$ and the inguinal adipose tissue was massively hypertrophied $(2.0 \pm 0.12$ vs. $0.5 \pm 0.02 \mathrm{~g} ; P$ $<0.01)$. The increase in inguinal adipose tissue in the mutant rats was fully accounted for by an increase in fat cell size (see Table I). It has been observed in our (23) and other (24) laboratories that during suckling, insulinemia levels were similar in obese and lean pups. This has been subsequently confirmed in many studies by different groups. Thus, insulin levels were not systematically investigated here, and we only measured a few samples that confirmed the similarity of both genotypes, with insulinemia in the range of 0.13 to $0.16 \mathrm{nM}$, at $16 \mathrm{~d}$ of age. At $30 \mathrm{~d}$ of age, obese rats have developed a frank hyperinsulinemia $(0.74$ vs. $0.28 \mathrm{nM})$. At both ages, obese rats were normoglycemic, with plasma glucose concentrations in the range of 7.9 to $8.6 \mathrm{mM}$ for lean rats vs. 8.4 to $9.1 \mathrm{mM}$ for obese rats.
Table I. Cell Size and Glucose Transport Activity of Adipose Cells from Young Zucker Rats

\begin{tabular}{cccc}
\hline & Cell size & \multicolumn{2}{c}{$6{ }^{14} \mathrm{C}$ Glucose uptake } \\
\hline & $n g$ lipid/cell & \multicolumn{2}{c}{ nmol/106 cells per min } \\
$16 \mathrm{~d}$ old & & Basal & Insulin $(0.72 \mathrm{nM})$ \\
Lean & $22 \pm 3(6)$ & $34 \pm 4(4)$ & $254 \pm 34(4)$ \\
Obese & $41 \pm 3(6)$ & $65 \pm 11(4)$ & $538 \pm 63(4)$ \\
$30 \mathrm{~d}$ old & & & \\
Lean & $44 \pm 8(7)$ & $54 \pm 7(6)$ & $882 \pm 16(6)$ \\
Obese & $184 \pm 8(7)$ & $155 \pm 23(6)$ & $3824 \pm 374(6)$ \\
\hline
\end{tabular}

Data are expressed as mean $\pm \mathrm{SEM}$, with the number of experiments in parentheses. Each value in obese rat is significantly different $(P<0.05)$ from the corresponding value in lean control (Student's $t$ test).

The rates of glucose uptake in adipocytes from lean and obese Zucker rats are presented in Table I. At $16 \mathrm{~d}$ of age, both basal and insulin-stimulated glucose transport rates were already two-fold higher in adipocytes from obese rats than in those from their lean littermates. The difference between the two genotypes enlarged after weaning and, at $30 \mathrm{~d}$ of age, the maximal activity of glucose transport, as assessed in the presence of physiological concentrations of insulin, was more than fourfold higher in adipocytes from obese rats than in those from lean rats. It is noteworthy that adipocytes from suckling pups exhibit a substantial responsiveness to insulin. However, both the absolute and the relative effects of the hormone on glucose transport activity are much lower in suckling than in weaned animals, in good agreement with our previous observations on adipocytes from rats fed a high-fat diet (25).

To get insight into the molecular mechanism underlying the increased glucose transport activity of adipose cells from the obese rats, the relative amount of GLUT 1 and GLUT 4 proteins was determined in fat cell membranes. The two types of antibody used in this study recognized proteins in the range of 45 to $50 \mathrm{kD}$. As shown in Fig. 1, the apparent molecular weights of these proteins were unchanged by the fa/fa genotype. In both lean and obese rats, the protein enrichment in GLUT 1 was higher in plasma than in intracellular mem-

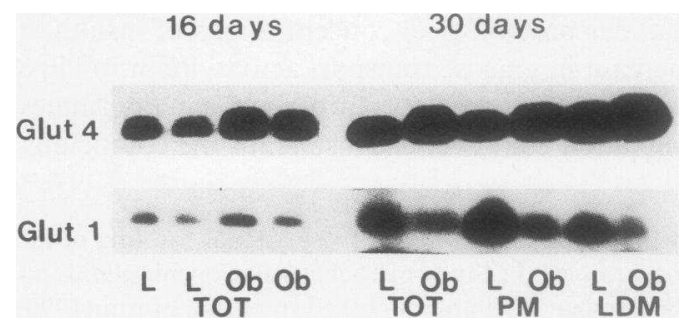

Figure 1. Immunological detection of GLUT 1 and GLUT 4 in adipocyte membranes from 16- or 30-d-old lean and obese Zucker rats. Membranes were prepared as described in Methods. Each lane was loaded with $100 \mu \mathrm{g}$ of proteins of total membranes (TOT), plasma membranes $(P M)$, or low-density microsomes $(L D M)$. Proteins were immunoblotted with a polyclonal antibody raised against the carboxy-terminal peptide of the erythroid glucose transporter (GLUT 1) or with a monoclonal antibody specific for the adipocyte/muscle-type glucose transporter (GLUT 4). These blots are representative of at least three experiments. $L$, lean rat; $O b$, obese rat. 
branes, whereas the protein enrichment in GLUT 4 was higher in the latter than in the former. The relative amount of GLUT 1 per milligram of total membrane proteins was similar in the two genotypes at $16 \mathrm{~d}$ of age (Fig. 1 and Table II), and decreased in obese as compared to lean rats in total membranes as well as in plasma and microsomal membranes at $30 \mathrm{~d}$ of age (Fig. 1 and Table III). In contrast, the relative amounts of GLUT 4 per milligram of protein were increased in obese as compared to lean rat adipose cells in all the membrane fractions examined (Fig. 1 and Tables II and III) at both ages. On a per-cell basis, the level of GLUT 1 protein was roughly unchanged by the genotype, whereas the level of GLUT 4 was increased in obese rat fat cells, by 2.4-fold and 4.5-fold at 16 and $30 \mathrm{~d}$ of age, respectively (Tables II and III). Therefore, as shown in Fig. 2, the genotype effect on adipocyte glucose transport activity was totally accounted for by changes in GLUT 4 protein mass per cell, in suckling as well as in weaning rats. It is of interest to note that the increase in GLUT 4 protein (2.4-fold) was higher than the increase in fat cell size (1.9-fold) at 16 of age and that the difference between these two effects narrowed at $30 \mathrm{~d}$ of age (4.5-fold vs. 4.2-fold). This lag of cell size enlargement behind GLUT 4 protein increase is suggestive of a cause and effect relationship between the increase in GLUT 4 and the increase in cell size.

We next addressed the question of the molecular mechanism of this differential regulation of the two transporter subtypes by the fatty genotype by examining the levels of GLUT 1 and GLUT 4 mRNA in adipose tissue. Both the GLUT 1 and GLUT 4 probes used in this study hybridized each to a single mRNA transcript, the size of which $(\simeq 2.7-2.8 \mathrm{~Kb})$ was unaltered by the fatty genotype (data not shown). As shown in Tables II and III, GLUT 1 mRNA levels per gram of total RNA were similar ( $16 \mathrm{~d}$ of age) or decreased ( $30 \mathrm{~d}$ of age) in obese versus lean rats. In sharp contrast, the levels of GLUT 4 mRNA per microgram of total RNA were markedly increased in the obese rats, 2.1 - and 3.6-fold at 16 and $30 \mathrm{~d}$ of age, respec-

Table II. Effect of the Fatty Genotype on the Levels of GLUT 1 and GLUT 4 Proteins and mRNAs in Adipose Tissue of 16-d-old Zucker Rats

\begin{tabular}{|c|c|c|}
\hline & Lean & Obese \\
\hline & \multicolumn{2}{|c|}{ GLUT 1} \\
\hline \multicolumn{3}{|l|}{ Protein* per } \\
\hline$\mu \mathrm{g}$ protein $^{\ddagger}$ & $3.4 \pm 0.4(3)$ & $3.7 \pm 0.1(3)$ \\
\hline $10^{6}$ fat cells & $184 \pm 13(3)$ & $268 \pm 40(3)$ \\
\hline \multicolumn{3}{|l|}{ mRNA ${ }^{8}$ per } \\
\hline$\mu \mathrm{g}$ RNA & $6.4(2)$ & $6.9 \pm 0.8(3)$ \\
\hline \multirow[t]{2}{*}{ fat pad } & $286(2)$ & $338 \pm 40(3)$ \\
\hline & \multicolumn{2}{|c|}{ GLUT 4} \\
\hline \multicolumn{3}{|l|}{ Protein per } \\
\hline$\mu \mathrm{g}$ protein & $19 \pm 3.2(6)$ & $35 \pm 2.4(6)^{\| \prime}$ \\
\hline $10^{6}$ fat cells & $983 \pm 123(5)$ & $2408 \pm 308(6)^{\|}$ \\
\hline \multicolumn{3}{|l|}{ mRNA per } \\
\hline$\mu \mathrm{g}$ RNA & $26 \pm 3.7(6)$ & $54 \pm 10(6)^{7}$ \\
\hline fat pad & $1096 \pm 148(6)$ & $2567 \pm 607(6)^{1}$ \\
\hline
\end{tabular}

Data are expressed as mean $\pm \mathrm{SEM}$, with the number of experiments in parentheses. ${ }^{*} \mathrm{cpm} .{ }^{*}$ Total membrane proteins. ${ }^{8}$ Arbitrary densitometric units. " $P<0.01$ and ' $P<0.05$ vs. lean (Student's $t$ test).
Table III. Effect of the Fatty Genotype on the Levels of GLUT 1 and GLUT 4 Proteins and $m R N A s$ in Adipose Tissue of 30-d-old Zucker Rats

\begin{tabular}{|c|c|c|}
\hline & Lean & Obese \\
\hline & \multicolumn{2}{|c|}{ GLUT 1} \\
\hline \multicolumn{3}{|l|}{ Protein* per } \\
\hline$\mu \mathrm{g}$ protein ${ }^{\ddagger}$ & $7.2 \pm 1.2(4)$ & $3.1 \pm 0.9(4)^{8}$ \\
\hline $10^{6}$ fat cells & $386 \pm 46(4)$ & $445 \pm 137(4)$ \\
\hline \multicolumn{3}{|l|}{ mRNA" per } \\
\hline$\mu \mathrm{g}$ RNA & $7.0 \pm 0.9(7)$ & $4.3 \pm 0.8(7)^{8}$ \\
\hline \multirow[t]{2}{*}{ fat pad } & $1637 \pm 176(6)$ & $1556 \pm 301(7)$ \\
\hline & \multicolumn{2}{|c|}{ GLUT 4} \\
\hline \multicolumn{3}{|l|}{ Protein per } \\
\hline$\mu \mathrm{g}$ protein & $40 \pm 3.8(6)$ & $56 \pm 4.3(6)^{8}$ \\
\hline $10^{6}$ fat cells & $2012 \pm 123(6)$ & $9146 \pm 2142(6)^{\prime}$ \\
\hline \multicolumn{3}{|l|}{ mRNA per } \\
\hline$\mu \mathrm{g}$ RNA & $23 \pm 1.0(9)$ & $84 \pm 17(9)^{\prime}$ \\
\hline fat pad & $4859 \pm 203(9)$ & $30206 \pm 6001(9)^{1}$ \\
\hline
\end{tabular}

Data are expressed as mean $\pm \mathrm{SEM}$, with the number of experiments in parentheses. ${ }^{*} \mathrm{cpm}$. ${ }^{\ddagger}$ Total membrane proteins. ${ }^{\S} P<0.05$ vs. lean (Student's $t$ test). "Arbitrary densitometric units. ' $P<0.01$ vs. lean (Student's $t$ test).

tively. Hybridization of the same blots with an actin cDNA probe showed minor changes between the two genotypes (data not shown), supporting the specificity of the variations in GLUT 1 and GLUT 4 mRNA. When normalized to the total RNA content of the fat pad, we observed a similar content of GLUT 1 mRNA in the two genotypes, whereas GLUT 4 mRNA was 2.3-fold and 6.2-fold higher in obese rats than in lean controls at 16 and $30 \mathrm{~d}$ of age, respectively (Tables II and
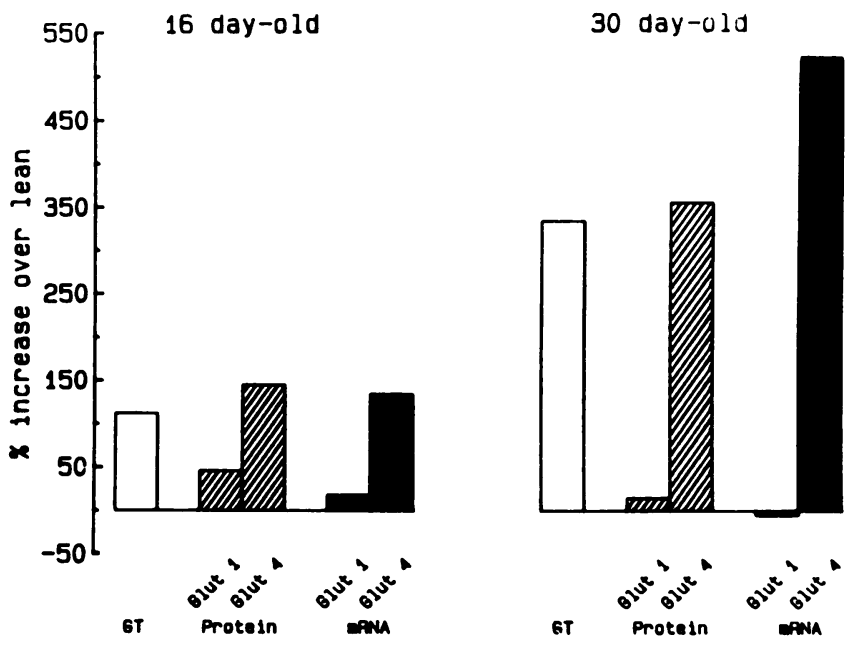

Figure 2. Genotype effect on insulin-stimulated glucose transport $(G T)$, GLUT 1 and GLUT 4 proteins per fat cell (שa) and GLUT 1 and GLUT 4 mRNA per fat pad ( $\square)$, in Zucker rats 16 or $30 \mathrm{~d}$ old. Results are expressed in percent increases over lean rat values. Data are compiled out of the results presented in Table I (GT), and 2 and 3 (GLUT 1 and GLUT 4 proteins and mRNA, in 16- and 30-d-old rats, respectively). With the same expression of the data, the genotype effect on fat cell size (Table I) was $+86 \%$ at $16 \mathrm{~d}$ and $+318 \%$ at 30 $\mathrm{d}$ of age. 
III). As evidenced in Fig. 2, the changes in GLUT 4 mRNA per total tissue between the two genotypes paralleled closely the changes in GLUT 4 protein per fat cell, suggesting that the increase in GLUT 4 mRNA mainly occurred within the adipocyte fraction of the tissue. The observation that GLUT 4 mRNA was virtually undetectable in the stroma-vascular cell fraction of the tissue whatever the rat genotype (data not shown) supported this conclusion.

To investigate whether the overexpression of GLUT 4 mRNA was a general feature of insulin-responsive tissues in the obese rat, we examined GLUT 4 mRNA levels in a skeletal muscle, the gastrocnemius. In contrast to adipose tissue, there was no consistent effect of the genotype on GLUT 4 mRNA expression in this muscle (Fig. 3). Further investigation of GLUT 4 mRNA levels in gastrocnemius muscle demonstrated that there was no significant difference between the two groups of rats (genotype effect, in percent over lean values: $-4 \pm 20$, for seven pairs of rats).

\section{Discussion}

The genetic obesity of the fa/fa rat, first described by Zucker and Zucker (26), is due to a single recessive autosomal gene mutation, as yet unidentified. This rat develops a syndrome which shares many features with human obesity: fat cell hypertrophy, hyperphagia, hyperinsulinemia, hyperlipemia, and normoglycemia. This experimental model of obesity may provide a useful model for the human disease where genetic factors play a major role (27).

Previous work has shown that adipocytes from young obese Zucker rats exhibit a hyperresponsive insulin-mediated glucose transport together with a marked increase in glucose transporters as assessed by using cytochalasin $B$ binding (1). The purpose of this work was to elucidate the molecular basis of this alteration, more specifically to address the question of which glucose transporter isoform was involved. The present data show that the genotype-linked increase in insulin-stimulated glucose transport activity is paralleled by a corresponding increase in the cell amount of GLUT 4 protein, whereas the abundance of GLUT 1 protein is unchanged. Furthermore, GLUT 4 mRNA

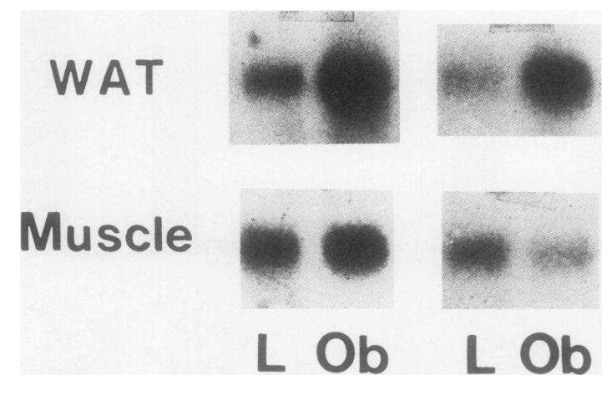

Figure 3. Northern-blot analysis of GLUT 4 mRNA from adipose tissue and muscle from Zucker rats $30 \mathrm{~d}$ old. RNA was extracted from inguinal fat pad (WAT) or from the gastrocnemius muscle (Muscle) of the same rats. Northern analysis was performed as described in Methods. $20 \mu \mathrm{g}$ of total RNA were loaded in each lane and blots were hybridized with a cRNA probe specific for the adipose cell/muscle-type glucose transporter (GLUT 4). These blots are from two different experiments. $L$, lean rat; $O b$, obese rat. levels per fat pad are increased proportionately to changes in GLUT 4 protein, whereas GLUT 1 mRNA is not affected by the fatty genotype. All together our data clearly show that the two adipocyte glucose transporter species are subject to differential regulation in the fatty rat model.

A similar pattern of regulation, in which an increase in GLUT 4 expression is associated with unchanged levels of GLUT 1 expression, has been previously reported in adipocytes of rats whose insulinemia levels were increased (insulin treatment of streptozotocin diabetes or fasting-refeeding, 1114), suggesting that insulin could be a major regulatory factor in determining GLUT 4 gene expression. Our observation that GLUT 4 is overexpressed in 16-d-old normoinsulinemic suckling obese pups conclusively establishes that the fa gene regulates GLUT 4 expression independent of hyperinsulinemia. This is the first demonstration that GLUT 4 expression in adipose tissue is under genotype control. The finding that the levels of GLUT 4 mRNA are unchanged in obese rat gastrocenmius muscle discloses the tissue specificity of this genotypic regulation.

We questioned whether the amplification of the genotype effect observed after weaning could be ascribed to insulin. However, recently, several sets of observations have made the role of hyperinsulinemia in chronic regulation of adipocyte GLUT 4 expression unclear. It has been shown that, in chronic insulin treatment of streptozotocin-diabetic rats, GLUT 4 mRNA levels which are initially elevated twofold above control rats in adipose tissue, decline to normal steady-state level within $7 \mathrm{~d}$ of insulin therapy, and then remain constant (28). Hyperinsulinemic 5-wk-old $\mathrm{db} / \mathrm{db}$ mice do not exhibit any alteration in GLUT 4 gene expression in adipose tissue (29). Finally chronic insulin treatment of either 3T3 L1 (30) or 3T3 F442A (21) cultured adipose cells has no significant effect on GLUT 4 expression.

The overexpression of GLUT 4 found here in adipocytes of Zucker mutant pups could play a determinant role in the induction of fat cell hypertrophy, an early phenotypic trait that develops before the onset of hyperphagia and hyperinsulinemia (31). The abundance of GLUT 4 protein would entail a hyperresponsive glucose transport activity to insulin, providing large supplies of lipid synthesis precursors. In addition, through an increased level of glycolytic intermediates, the overexpression of GLUT 4 might be responsible for the induction of the array of enzymes, such as lipoprotein lipase, fatty acid synthetase, and malic enzyme, that has been observed in adipocytes of very young obese pups $(23,31)$ because those enzymes have been reported to be under the regulation of specific intermediary metabolites (32-34). Thus, GLUT 4 overexpression would act as a "metabolic pull" channeling substrates into adipose tissue triglycerides whatever the food intake levels, a prominent metabolic feature of the obese Zucker rat (35-37).

The proportionate changes in insulin-induced glucose transport activity, GLUT 4 protein mass and GLUT 4 mRNA levels, strongly suggest that the genetic regulation of GLUT 4 expression disclosed here occurs at a pretranslational level. This raises the important question of whether GLUT 4 mRNA content is increased through an increase in gene transcription and/or in GLUT 4 mRNA stability. Given the potential role of the increased expression of GLUT 4 in the etiology of inherited obesity, the possibility that GLUT 4 gene is either the primary site of the mutation or a close target of the mutated gene, deserves investigation. 


\section{Acknowledgments}

We wish to thank Drs. S. W. Cushman, P. F. Pilch, M. J. Charron, and M. J. Birnbaum for their kind gift of probes.

This work was supported by a grant from the Fondation pour la Recherche Medicale.

\section{References}

1. Guerre-Millo, M., M. Lavau, J. S. Horne, and L. J. Wardzala. 1985. Proposed mechanism for increased insulin-mediated glucose transport in adipose cells from young, obese Zucker rats. Large intracellular pool of glucose transporters. J. Biol. Chem. 260:2197-2201.

2. Krief, S., R. Bazin, F. Dupuy, and M. Lavau. 1988. Increased in vivo glucose utilization in 30-day-old obese Zucker rats: role of white adipose tissue. Am. J. Physiol. 254:E342-E348.

3. Mueckler, M., C. Caruso, S. A. Baldwin, M. Panico, I. Blench, H. R. Morris, W. J. Allard, G. E. Leinhard, and H. F. Lodish. 1985. Sequence and structure of a human glucose transporter. Science (Wash. DC). 229:941-945.

4. Birnbaum, M. J., H. C. Haspel, and O. M. Rosen. 1986. Cloning and characterization of a cDNA encoding the rat brain glucose-transporter protein. Proc. Natl. Acad. Sci. USA. 83:5784-5788.

5. Asano, T., Y. Shibasaki, M. Kasuga, Y. Kanazawa, F. Takaku, Y. Akanuma, and Y. Oka. 1988. Cloning of a rabbit brain transporter cDNA and alteration of glucose transporter mRNA during tissue development. Biochem. Biophys. Res. Commun. 154:1204-1211.

6. James, D. E., R. Brown, J. Navarro, and P. F. Pilch. 1988. Insulin-regulatable tissues express a unique insulin-sensitive glucose transport protein. Nature (Lond.). 333:183-185.

7. Kaestner, K. H., R. J. Christy, J. C. McLenithan, L. T. Braiterman, P. Cornelius, P. H. Pekala, and M. D. Lane. 1989. Sequence, tissue distribution, and differential expression of $\mathrm{mRNA}$ for a putative insulin-responsive glucose transporter in mouse 3T3-L1 adipocytes. Proc. Natl. Acad. Sci. USA. 86:3150-3154.

8. Charron, M. J., M. J. Brosius III, S. L. Alper, and H. F. Lodish. 1989. A glucose transport protein expressed predominantly in insulin-responsive tissues. Proc. Natl. Acad. Sci. USA. 86:2535-2539.

9. Birnbaum, M. J. 1989. Identification of a novel gene encoding an insulinresponsive glucose transport protein. Cell. 57:305-315.

10. Fukumoto, H., T. Kayano, J. B. Buse, Y. Edwards, P. F. Pilch, G. I. Bell, and S. Seino. 1989. Cloning and characterization of the major insulin-responsive glucose transporter expressed in human skeletal muscle and other insulin-responsive tissues. J. Biol. Chem. 264:7776-7779.

11. Kahn, B. B., M. J. Charron, H. F. Lodish, S. W. Cushman, and J. S. Flier. 1989. Differential regulation of two glucose transporters in adipose cells from diabetic and insulin-treated diabetic rats. J. Clin. Invest. 84:404-411.

12. Berger, J., C. Biswas, P. P. Vicario, H. V. Strout, R. Saperstein, and P. F. Pilch. 1989. Decreased expression of the insulin-responsive glucose transporter in diabetes and fasting. Nature (Lond.). 340:70-72.

13. Sivitz, W. I., S. L. DeSautel, T. Kayano, G. I. Bell, and J. E. Pessin. 1989. Regulation of glucose transporter messenger RNA in insulin-deficient states. $\mathrm{Na}$ ture (Lond.). 340:72-74.

14. Garvey, W. T., T. Huecksteadt, and M. J. Birnbaum. 1989. Pretranslational suppression of an insulin-responsive glucose transporter in rats with diabetes mellitus. Science (Wash. DC). 254:60-63.

15. Bazin, R., and M. Lavau. 1982. Development of hepatic and adipose tissue lipogenic enzymes and insulinemia during suckling and weaning on to a high-fat diet in Zucker rats. J. Lipid. Res. 23:839-849.

16. Lavau, M., and R. Bazin. 1982. Inguinal fat pad weight plotted versus body weight as a method of genotype identification in 16-day-old Zucker rats. $J$. Lipid Res. 23:941-943.

17. Rodbell, M. 1964. Metabolism of isolated fat cells. I. Effects of hormones on glucose metabolism and lipolysis. J. Biol. Chem. 239:375-380.

18. Guerre-Millo, M., A. Leturque, J. Girard, and M. Lavau. 1985. Increased insulin sensitivity and responsiveness of glucose metabolism in adipocytes from female versus male rats. J. Clin. Invest. 76:109-116.

19. Lavau, M., C. Susini, J. Knittle, S. Blanchet-Hirst, and M. R. C. Greenwood. 1977. A reliable photomicrographic method for determining fat cell size and number: application to dietary obesity. Proc. Soc. Exp. Biol. Med. 156:251256.

20. Haspel, H. C., M. G. Rosenfeld, and O. M. Rosen. 1988. Characterization of antisera to a synthetic carboxyl-terminal peptide of the glucose transporter protein. J. Biol. Chem. 263:398-403.

21. Hainque, B., M. Guerre-Millo, I. Hainault, N. Moustaid, and M. Lavau. 1990. Long-term regulation of glucose transporters by insulin in mature 3T3 F442A adipose cells. Differential effects on two transporter sub-types. J. Biol. Chem. 265:7982-7986.

22. Cathala, G., J. F. Savouret, B. Mendez, B. L. West, M. Karin, J. A. Martial, and J. D. Baxter 1983. A method for isolation of intact, translationally active ribonucleic acid. DNA 2:329-335.

23. Bazin, R., and M. Lavau. 1982. Development of hepatic and adipose tissue lipogenic enzymes and insulinemia during suckling and weaning on to a high-fat diet in Zucker rats. J. Lipid. Res. 23:839-849.

24. Zucker, L., and H. N. Antoniades. 1972. Insulin and obesity in the Zucker genetically obese rat "fatty". Endocrinology. 90:1320-1330.

25. Lavau, M., S. K. Fried, C. Susini, and P. Freychet. 1979. Mechanism of insulin resistance in adipocytes of rats fed a high-fat diet. J. Lipid Res. 20:8-16.

26. Zucker, L. M., and T. F. Zucker. 1961. Fatty, a new mutation in the rat. $J$. Hered. 52:275-278.

27. Stunkard, A. J., T. I. A. Sorensen, C. Harris, T. W. Teasdale, R. Chakraborty, W. J. Schull, and F. Schulsinger. 1986. An adoption study of human obesity. N. Engl. J. Med. 314:193-198.

28. Sivitz, W. I., S. L. DeSautel, T. Kayano, G. I. Bell, and J. E. Pessin. 1990. Regulation of glucose transporter messenger RNA levels in rat adipose tissue by insulin. Mol. Endocrinol. 4:583-588.

29. Koryani, L., D. James, M. Mueckler, and M. A. Permutt. 1990. Glucose transporter levels in spontaneously obese $(\mathrm{db} / \mathrm{db})$ insulin-resistant mice. J. Clin. Invest. 85:962-967.

30. Tordjman, K. M., K. A. Leingang, D. E. James, and M. M. Mueckler. 1989. Differential regulation of two distinct glucose transporter species expressed in 3T3-L1 adipocytes: effect of chronic insulin and tolbutamide treatment. Proc. Natl. Acad. Sci. USA. 86:7761-7765.

31. Boulangé, A., E. Planche, and P. de Gasquet. 1979. Onset of genetic obesity in the absence of hyperphagia during the first week of life in the Zucker rat (fa/fa). J. Lipid Res. 20:857-864.

32. Spooner, P. M., S. S. Chernick, M. M. Garisson, and R. O. Scow. 1979. Insulin regulation of lipoprotein lipase activity and release in 3T3-L1 adipocytes. J. Biol. Chem. 254:10021-10029.

33. Volpe, J. J., and J. C. Marassa. 1975. Hormonal regulation of fatty acid synthetase, acetyl coA carboxylase and fatty acid synthesis in mammalian adipose tissue and liver. Biochim. Biophys. Acta. 380:454-472.

34. Mariash, C. N., and H. L. Schwartz. 1986. Effect of Dichloroacetic acid on rat hepatic messenger RNA activity profiles. Metabolism. 35:452-456.

35. Zucker, L. M. 1967. Some effects of caloric restriction and deprivation on the obese hyperlipidemic rat. J. Nutr. 91:247-254.

36. Bray, G. A., D. A. York, and R. S. Swerloff. 1973. Genetic in rat. I. The effect of food restriction on body composition and hypothalamic function. Metabolism. 22:435-442.

37. Cleary, M. P., J. R. Vasselli, and M. R. C. Greenwood. 1980. Development of obesity in Zucker obese (fa/fa) rat in absence of hyperphagia. Am. J. Physiol. 238:284-292. 